\title{
A Novel Gain-of-Function Nav1.9 Mutation in a Child With Episodic Pain
}

\author{
Jianying Huang 1,2, Mark Estacion 1,2, Peng Zhao ${ }^{1,2}$, Fadia B. Dib-Hajj,1,2, \\ Betsy Schulman ${ }^{1,2}$, Angela Abicht ${ }^{3,4}$, Ingo Kurth ${ }^{5}$, Knut Brockmann ${ }^{6}$, \\ Stephen G. Waxman ${ }^{1,2}$ and Sulayman D. Dib-Hajj ${ }^{1,2 *}$
}

\begin{abstract}
1 'Department of Neurology, Center for Neuroscience and Regeneration Research, Yale University School of Medicine, New Haven, CT, United States, ${ }^{2}$ Rehabilitation Research Center, Veterans Affairs Connecticut Healthcare System, West Haven, CT, United States, ${ }^{3}$ Medizinisch Genetisches Zentrum, Munich, Germany, ${ }^{4}$ Department of Neurology,

Friedrich-Baur-Institute, Ludwig-Maximilians-University of Munich, Munich, Germany, ${ }^{5}$ Medical Faculty, Institute of Human Genetics, RWTH Aachen University, Aachen, Germany, ${ }^{6}$ Department of Pediatrics and Pediatric Neurology, Georg August University, Göttingen, Germany
\end{abstract}

OPEN ACCESS

Edited by:

Nurcan Üçeyler,

Julius Maximilian University of Würzburg, Germany

Reviewed by:

Robert Blum

Julius Maximilian University of Würzburg, Germany

Tim Hagenacker,

Essen University Hospital, Germany

Patrick M. Dougherty,

University of Texas MD Anderson Cancer Center, United States

*Correspondence:

Sulayman D. Dib-Hajj sulayman.dib-hajj@yale.edu

Specialty section: This article was submitted to

Perception Science,

a section of the journal

Frontiers in Neuroscience

Received: 03 July 2019

Accepted: 16 August 2019 Published: 03 September 2019

Citation:

Huang J, Estacion M, Zhao P, Dib-Hajj FB, Schulman B, Abicht $A$, Kurth I, Brockmann K, Waxman SG and Dib-Haij SD (2019) A Novel Gain-of-Function Nav1.9 Mutation in a Child With Episodic Pain.

Front. Neurosci. 13:918. doi: 10.3389/fnins.2019.00918
Voltage-gated sodium channel Nav1.9 is a threshold channel that regulates action potential firing. Nav1.9 is preferentially expressed in myenteric neurons, and smalldiameter dorsal root ganglion (DRG) and trigeminal ganglion neurons including nociceptors. Recent studies have demonstrated a monogenic Mendelian link of Nav1.9 to human pain disorders. Gain-of-function variants in Nav1.9, which cause smaller depolarizations of RMP, have been identified in patients with familial episodic pain type 3 (FEPS3) and the more common pain disorder small fiber neuropathy. To explore the phenotypic spectrum of Nav1.9 channelopathy, here we report a new Nav1.9 mutation, N816K, in a child with early-onset episodic pain in both legs, episodic abdominal pain, and chronic constipation. Sequencing of further selected pain genes was normal. N816K alters a residue at the $\mathrm{N}$-terminus of loop 2, proximal to the cytoplasmic terminus of transmembrane segment 6 in domain II. Voltage-clamp recordings demonstrate that Nav1.9-N816K significantly increases current density and hyperpolarizes voltagedependence of activation by $10 \mathrm{mV}$, enabling a larger window current. Current-clamp recordings in DRG neurons shows that N816K channels depolarize RMP of small DRG neurons by $7 \mathrm{mV}$, reduce current threshold of firing an action potential and render DRG neurons hyperexcitable. Taken together these data demonstrate gain-of-function attributes of the newly described N816K mutation at the channel and cellular levels, which are consistent with a pain phenotype in the carrier of this mutation.

Keywords: channelopathy, DRG, pain, sodium channel, SCN11A, excitability

\section{INTRODUCTION}

Voltage-gated sodium channel Nav1.9 is preferentially expressed in small-diameter sensory neurons of dorsal root ganglia (DRG) and trigeminal ganglia, which include high-threshold nociceptors (Dib-Hajj et al., 1998). Nav1.9 channels can be detected along axons of non-myelinated fibers in sciatic nerve and cornea (Fjell et al., 2000; Black and Waxman, 2002; O'Brien et al., 2008), as well as in myenteric sensory neurons implicating Nav1.9 channel in intestinal reflex function 
(Rugiero et al., 2003; Coste et al., 2004; Padilla et al., 2007; Osorio et al., 2014). Nav1.9 channels in small DRG neurons from rodents and human produce a tetrodotoxin-resistant (TTXR) current with distinctive biophysical properties compared to other voltage-gated sodium channels, including hyperpolarized voltage-dependence of activation (at approximately $-80 \mathrm{mV}$ ), substantial window current (i.e., overlap of activation and steady-stated inactivation) in the voltage domain that includes resting membrane potential (RMP) of DRG neurons, marked persistent current and activation and inactivation slow kinetics (Cummins et al., 1999; Dib-Hajj et al., 1999). The large window current of Nav1.9 channel at physiologically relevant potentials suggests that the channel plays a significant role in regulating neuronal excitability. The anatomical distribution and functional properties support a role for Nav1.9 as a threshold channel (Bennett et al., 2019).

An increasing number of Nav1.9 mutations has been identified in patients with enhanced as well as diminished pain perception. Nav1.9 mutations identified in patients with adult-onset painful neuropathy or early-onset familial episodic pain type 3 (FEPS3) render small DRG neurons hyperexcitable, underlying enhanced pain as experienced by the patients (Zhang et al., 2013; Huang et al., 2014; Han et al., 2015, 2017; Leipold et al., 2015; Okuda et al., 2016). Gain-of-function attributes of these Nav1.9 mutants include a hyperpolarizing shift in voltage-dependence of activation by 6-10 $\mathrm{mV}$, compared to wild-type channels (Huang et al., 2014; Han et al., 2015, 2017). An intriguing finding is that the gain-of-function mutations in transmembrane segment 6 of domain I (DI/S6-L396P), DII/S6-L811P, and DIII/S6L1302F in Nav1.9, which massively hyperpolarize activation by approximately 22-27 $\mathrm{mV}$, are found in subjects with a loss-ofpain perception (Leipold et al., 2013; Huang et al., 2017; King et al., 2017). The resulting increase of window current from such a massive hyperpolarizing shift in activation deeply depolarizes RMP of DRG neurons, leading to neuronal inexcitability at the cellular level, which underlies painless injuries at the clinical level (Huang et al., 2017). Thus, a spectrum of clinical phenotypes is produced by gain-of-function mutations in Nav1.9.

Here we report a novel mutation in human Nav1.9 channel found in a child with FEPS3. The N816K mutation is located at the juncture between transmembrane segment 6 of domain II (DII/S6) and L2, the loop that joins domains II and III, in proximity to the hydrophobic ring that stabilizes the closed state of sodium channels, which is formed by aromatic residues at the $\mathrm{C}$ terminus of each of the S6 segments in the four domains (Lampert et al., 2008). We characterized changes in biophysical properties of the mutant channel using voltage-clamp recordings and assessed firing properties of DRG neurons using currentclamp recordings. This study expands the spectrum of Nav1.9 channelopathies in patients with pain.

\section{MATERIALS AND METHODS}

\section{Plasmid}

The human wild-type GFP-2A-Na 1.9 plasmid was previously described (Huang et al., 2014). Briefly, a sequence encoding enhanced green fluorescent protein (EGFP) was cloned upstream of the human $\mathrm{Na}_{\mathrm{v}} 1.9$ ATG with a "stopGo" 33 amino acid 2A linker, which allows the GFP-2A adaptor and the $\mathrm{Na}_{\mathrm{v}} 1.9$ channel proteins to be produced as independent proteins from the same mRNA (Ryan and Drew, 1994; Atkins et al., 2007; Luke et al., 2008). The c.2448T > A (p.N816K) was introduced into the construct using QuikChange ${ }^{\circledR}$ II XL site-directed mutagenesis (Stratagene, La Jolla, CA, United States) and referred to as N816K channels hereinafter.

\section{Primary Sensory Neuron Isolation and Transfection for Whole-Cell Patch-Clamp Recordings}

Animal studies followed a protocol approved by Department of Veterans Affairs West Haven Medical Center Animal Use Committees. For voltage-clamp recording, DRG neurons were isolated from homozygous Nav1.9 $9^{-/}$mice (4-8 weeks old, both male and female) that lack endogenous Nav1.9 and transfected by electroporation as previously reported (Dib-Hajj et al., 2009). Briefly, DRGs were rapidly harvested, incubated at $37^{\circ} \mathrm{C}$ for $20 \mathrm{~min}$ in complete saline solution (CSS) [in $\mathrm{mM}$ : $137 \mathrm{NaCl}, 5.3 \mathrm{KCl}, 1 \mathrm{MgCl} 2,25$ sorbitol, $3 \mathrm{CaCl}$, and $10 \mathrm{~N}$-2-hydroxyethylpiperazine- $\mathrm{N}^{\prime}$-2-ethanesulfonic acid (Hepes), adjusted to $\mathrm{pH} 7.2$ with $\mathrm{NaOH}$ ] containing $0.5 \mathrm{U} / \mathrm{mL}$ Liberase TM (Sigma) and 0.6 mM EDTA, followed by a $15 \mathrm{~min}$ incubation at $37^{\circ} \mathrm{C}$ in CSS containing $0.5 \mathrm{U} / \mathrm{mL}$ Liberase TL (Sigma), $0.6 \mathrm{mM}$ EDTA, and $30 \mathrm{U} / \mathrm{mL}$ papain (Worthington Biochemical). DRGs were then centrifuged and triturated in $0.5 \mathrm{~mL}$ of DRG media: Dulbecco's modified Eagle's mediumF12 (1:1) with $100 \mathrm{U} / \mathrm{mL}$ penicillin, $0.1 \mathrm{mg} / \mathrm{mL}$ streptomycin (Invitrogen), and 10\% fetal bovine serum (Hyclone), containing $1.5 \mathrm{mg} / \mathrm{mL}$ BSA (low endotoxin; Sigma) and $1.5 \mathrm{mg} / \mathrm{mL}$ trypsin inhibitor (Sigma). After trituration, the cells were transfected with WT or mutant Nav1.9 constructs using a Nucleofector IIS (Lonza) and Amaxa Basic Neuron SCN Nucleofector Kit (VSPI1003), as described before (Huang et al., 2014, 2017). Briefly, the cell suspension was centrifuged $(100 \times \mathrm{g}$ for $3 \mathrm{~min})$, and the cell pellet was resuspended in $20 \mu \mathrm{L}$ of Nucleofector solution, mixed with $2.5 \mu \mathrm{g}$ of WT or N816K human Nav1.9 channels, and transfected using Nucleofector IIS and protocol SCN-BNP 6. After electroporation, $100 \mu \mathrm{L}$ of calcium-free DMEM $\left(37^{\circ} \mathrm{C}\right)$ was added, and cells were incubated at $37^{\circ} \mathrm{C}$ for $5 \mathrm{~min}$ to recover. The cell mixture was then diluted with DRG media containing $1.5 \mathrm{mg} / \mathrm{mL}$ BSA (low endotoxin) and $1.5 \mathrm{mg} / \mathrm{mL}$ trypsin inhibitor (Sigma), seeded onto poly-D-lysine/laminincoated coverslips (BD), and incubated at $37^{\circ} \mathrm{C}$ in a $95 \%$ air $/ 5 \%$ $\mathrm{CO} 2$ (vol/vol) incubator for $45 \mathrm{~min}$ for neurons to attach to the coverslips. After $45 \mathrm{~min}, 0.9 \mathrm{~mL}$ of DRG media supplemented with nerve growth factor $(50 \mathrm{ng} / \mathrm{mL})$ and glial cell line-derived neurotrophic factor $(50 \mathrm{ng} / \mathrm{mL}$ ) was added into each well, and the DRG neurons were maintained at $37^{\circ} \mathrm{C}$ in a $95 \%$ air $/ 5 \% \mathrm{CO}_{2}$ (vol/vol) incubator. Voltage-clamp recordings were performed approximately $65-75 \mathrm{~h}$ post-transfection.

For current-clamp recording, DRGs from 4 to 6 weeks old female and male Sprague-Dawley rats were harvested and dissociated as described previously (Dib-Hajj et al., 2009). Briefly, 
DRG neurons were dissociated with a 20 min incubation

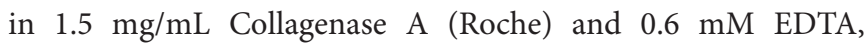
followed by a $17 \mathrm{~min}$ incubation in $1.5 \mathrm{mg} / \mathrm{mL}$ Collagenase D (Roche), $0.6 \mathrm{mM}$ EDTA, and $30 \mathrm{U} / \mathrm{mL}$ papain; DRGs were then centrifuged and triturated in $0.5 \mathrm{~mL}$ of DRG media containing $1.5 \mathrm{mg} / \mathrm{mL}$ BSA (low endotoxin) and $1.5 \mathrm{mg} / \mathrm{mL}$ trypsin inhibitor (Sigma). After trituration, $2 \mathrm{~mL}$ of DRG media was added to the cell suspension, which was filtered with $70 \mu \mathrm{m}$ nylon mesh cell strainer (Becton Dickinson). The mesh was washed twice with $2 \mathrm{~mL}$ of DRG media. The cells were then transfected as described above for voltage-clamp recording with $2.0 \mu \mathrm{g}$ of WT or N816K hNav1.9 channels. After transfection, cells were recovered in calcium-free DMEM, fed with DRG media supplemented with nerve growth factor $(50 \mathrm{ng} / \mathrm{mL})$ and glial cell line-derived neurotrophic factor $(50 \mathrm{ng} / \mathrm{mL})$, and maintained at $37^{\circ} \mathrm{C}$ in a $95 \%$ air $/ 5 \% \mathrm{CO}_{2}$ ( $\mathrm{vol} / \mathrm{vol}$ ) incubator for $45-55 \mathrm{~h}$ before current-clamp recording.

\section{Whole-Cell Patch-Clamp Recordings}

Voltage-clamp recordings were obtained at $22 \pm 1{ }^{\circ} \mathrm{C}$ using an EPC-10 amplifier (HEKA Electronics, Lambrecht/Pfalz, Germany). Fire-polished electrodes were fabricated from $1.6 \mathrm{~mm}$ outer diameter borosilicate glass micropipettes (World Precision Instruments) using a Sutter Instruments P-97 puller and had a resistance of $0.8-1.3 \mathrm{M} \Omega$. Transfected small DRG neurons $(<25 \mu \mathrm{m})$ from Nav1.9 $9^{-/-}$mice with robust green fluorescence and no apparent neurites were selected for voltage-clamp recording. The average diameter for small DRG neurons overexpressing wild-type hNav1.9 channels is not significantly different from those overexpressing N816K mutant hNav1.9 channels (WT: $21.0 \pm 0.68 \mu \mathrm{m}, n=18$; N816K: $21.2 \pm 0.65 \mu \mathrm{m}$, $n=20 ; p=0.804)$. The extracellular bath solution contained the following (in $\mathrm{mM}$ ): $140 \mathrm{NaCl}, 3 \mathrm{KCl}, 1 \mathrm{MgCl}_{2}, 1$ $\mathrm{CaCl}_{2}, 10 \mathrm{HEPES}, 5 \mathrm{CsCl}, 20$ tetraethylammonium chloride (TEA.Cl), pH 7.3 with $\mathrm{NaOH}$. Osmolarity was adjusted to $320 \mathrm{mOsmol} / \mathrm{L}$ with sucrose. Tetrodotoxin (1 $\mu \mathrm{M}), \mathrm{CdCl}_{2}$ $(0.1 \mathrm{mM})$, and 4-aminopyridine $(1 \mathrm{mM})$ were added to block endogenous tetrodotoxin-sensitive sodium currents, calcium currents, and potassium currents, respectively. The intracellular pipette solution contained the following (in $\mathrm{mM}$ ): $140 \mathrm{CsF}$, $10 \mathrm{NaCl}, 1$ EGTA, 10 HEPES, and 10 dextrose, $\mathrm{pH} 7.3$ with $\mathrm{CsOH}$. Osmolarity was adjusted to $310 \mathrm{mOsmol} / \mathrm{L}$ with sucrose. Sodium currents were acquired with Patchmaster at 5 min after establishing whole-cell configuration, sampled at $50 \mathrm{kHz}$, and filtered at $2.9 \mathrm{kHz}$.

Under whole-cell voltage-clamp configuration and guided by green fluorescence as evidence for expression of hNav1.9 channels, each individual neuron was held at $-120 \mathrm{mV}$ initially to record the total TTX-R sodium currents by a series of $100 \mathrm{~ms}$ step voltage commands from -120 to $+40 \mathrm{mV}$ in $5 \mathrm{mV}$ increments at $5 \mathrm{~s}$ intervals in order to elicit the total TTX-R sodium currents, which consist of hNav1.9 currents and endogenous mouse Nav1.8 TTX-R currents. The same cell was subsequently held at $-60 \mathrm{mV}$ to inactivate Nav1.9 channels (Cummins et al., 1999), prepulsed to $-120 \mathrm{mV}$ for $100 \mathrm{~ms}$ to allow Nav1.8 channels to recover from fast-inactivation, followed by $100 \mathrm{~ms}$ step voltage commands from -120 to $+40 \mathrm{mV}$, which elicited the intact endogenous mouse Nav1.8 currents. Nav1.9 currents were generated by subtracting Nav1.8 currents from total TTX-R sodium currents. Linear leak currents were subtracted out using the $\mathrm{P} / \mathrm{N}$ method. Seventy five to eighty five percent compensation was applied. Cells were excluded from analysis if the predicted voltage error (Verr) is greater than $5 \mathrm{mV}$, calculated by Verr $=I$ Ipeak ${ }^{*} s^{*}(1-\operatorname{Comp} \%)$, where Ipeak is the maximal peak sodium current, $R s$ is the series resistance, and Comp\% is the percentage of compensation. There is no significant difference in voltage error between WT and N816K (WT: $1.83 \pm 0.25 \mathrm{mV}, n=13$; N816K: $2.37 \pm 0.36 \mathrm{mV}$, $n=12 ; p=0.231)$. Voltage-dependence of activation for Nav1.9 channels were fit with Boltzmann functions in the form of $G=G_{\max } /\left(1+\exp \left[\left(V_{1 / 2}\right.\right.\right.$, act $\left.\left.\left.-V\right) / k\right]\right)$, where $G_{\max }$ is the maximal conductance, $V_{1 / 2}$, act is the voltage at which activation is halfmaximal, $V$ is the test voltage and $k$ is the slope factor. Steadystate fast inactivation was assessed by measuring the remaining non-inactivated channels by depolarizing the cell to $-45 \mathrm{mV}$ for $50 \mathrm{~ms}$, a voltage near which peak Nav1.9 currents are recorded, following a series of $500 \mathrm{~ms}$ prepulses from -130 to $10 \mathrm{mV}$ in $10 \mathrm{mV}$ increments. Normalized peak inward currents were fit with Boltzman functions: $I / I_{\max }=A+(1-A) /(1+\exp [(V$ $\left.\left.\left.-V_{1 / 2 \text {,fast }}\right) / \mathrm{k}\right]\right)$, where $V$ represents the inactivating prepulse voltage, $V_{1 / 2}$, fast represents the midpoint of the steady-state fast inactivation.

Action potentials were recorded by current-clamp experiments in adult rat small $(<30 \mu \mathrm{m}$ in diameter $)$ DRG neurons transfected with WT or N816K mutant hNav1.9 channels, guided by green fluorescence. The average diameter for neurons expressing WT or N816K is $27.5 \pm 0.27(n=39)$, and $27.0 \pm 0.25(n=43)(p=0.155)$, respectively. Electrodes had a resistance of 1.0-1.8 $\mathrm{M} \Omega$ when filled with the pipette solution, which contained the following (in $\mathrm{mM}$ ): $140 \mathrm{KCl}$, 0.5 EGTA, 5 HEPES, 10 dextrose, and $3 \mathrm{Mg}$-ATP, pH 7.3 with $\mathrm{KOH}$. Osmolarity was adjusted to $310 \mathrm{mOsm} / \mathrm{L}$ with sucrose. The extracellular solution contained the following (in $\mathrm{mM}$ ): 140 $\mathrm{NaCl}, 3 \mathrm{KCl}, 2 \mathrm{MgCl}_{2}, 2 \mathrm{CaCl}_{2}, 10 \mathrm{HEPES}$, and 10 dextrose, $\mathrm{pH}$ 7.3 with $\mathrm{NaOH}$. Osmolarity was adjusted to $320 \mathrm{mOsm} / \mathrm{L}$ with sucrose. Whole-cell configuration was obtained in voltage-clamp mode before proceeding to the current-clamp recording mode. Threshold was determined by the first action potential elicited by a series of $200 \mathrm{~ms}$ depolarizing current injections that increased in $5 \mathrm{pA}$ increments. Repetitive firing was evaluated by a series of $500 \mathrm{~ms}$ depolarizing current injections from 25 to $500 \mathrm{pA}$ in $25 \mathrm{pA}$ increments. Neurons that fired spontaneously (i.e., without external current stimuli) were excluded from analysis of RMP, input resistance, current threshold, amplitude, half-width, or after-hyperpolarization potential.

\section{Data Analysis}

Electrophysiological data were analyzed using Fitmaster (HEKA Electronics) and Origin 9 (Microcal, Northampton, MA, United States), and presented as means \pm standard error. Statistical significance was determined by independent Student's $t$-tests. Mann-Whitney test was used to compare frequency of evoked firing in response to graded external stimuli. Twoproportion $z$-test was used in comparisons of proportion 
of cells producing spontaneous activity and proportion of cells firing repetitively). A $p$-value of less than 0.05 is considered statistically significant.

\section{RESULTS}

\section{Clinical Phenotype}

Informed consent of the parents of this child was obtained before the initiation of the study, which was approved by the local ethics committee at the Uniklinik under an approved institutional review board. The novel N816K mutation in human Nav1.9 channel was found in a 7 years old girl with familial episodic pain in her legs with onset at 6 months of age. At the time of study she complained of massive pain that occurred every evening; she reported that naproxen (NSAID) alleviated the pain. In addition, she described episodes of abdominal pain with onset at 6 years of age, and a history of chronic constipation since her first months of life. Diagnostic work-up including rectal biopsy revealed no abnormal findings. Nerve conduction studies were normal. Sweating was normal, and there was no sensory disturbance. The clinical features of this girl corresponded to the descriptions of familial episodic pain type 3 (FEPS3; OMIM \#615552) associated with heterozygous SCN11A variants.

Motor development of this girl was mildly slower than in her older sister; she walked without support at 18 months of age. At age 7 years, muscle strength and motor endurance were reduced. Her maximal walking distance was $200 \mathrm{~m}$ during daytime and $100 \mathrm{~m}$ in the evening, after which she then needed to sit down for a short break. Cold or heat did not trigger pain episodes or influence motor performance. On physical examination, there were mild muscular hypotonus, joint hypermobility and mild proximally pronounced muscle weakness. Muscle stretch reflexes were normal.

A molecular genetic panel for painful neuropathy showed the heterozygous variant c.2448T > A; p.(Asn816Lys); N816K in the SCN11A gene (ENST00000302328). This extremely rare variant (rs376128467) has been reported only once in 250,714 alleles in the Genome Aggregation database (gnomAD) ${ }^{1}$, and has not been reported among the few patients with episodic pain due to SCN11A mutations. Further genetic testing included SCN9A, SCN10A, TRPA1 - all with normal results. Interestingly, the father of the proband is a carrier of this mutation but has not experienced any of these symptoms.

\section{Biophysical Properties of N816K Mutant hNav1.9 Channel}

The N816K substitution alters a residue at the N-terminus of loop 2, proximal to the cytoplasmic terminus of transmembrane segment 6 in domain II (DII/S6) (Figure 1). While N816 is conserved in Nav1.9 rodent orthologs, it is not conserved in the other human voltage-gated sodium channels, where the corresponding residue is either an alanine or a serine (Figure 1). The location of N816 is one residue away from the highly conserved phenylalanine that has been implicated in forming the

${ }^{1}$ https://gnomad.broadinstitute.org/

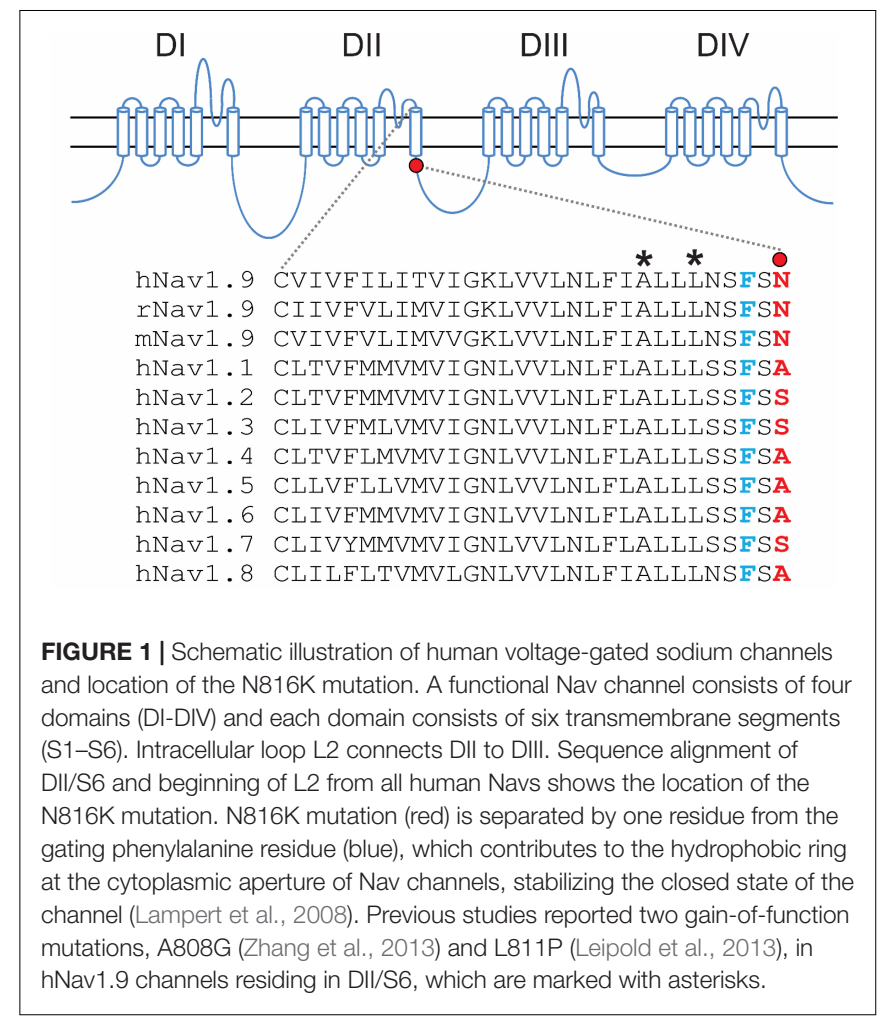

hydrophobic ring with the corresponding residues in S6 segments of the other domains, and which stabilizes the closed state of the channel (Lampert et al., 2008).

The introduction of a positive charge proximal to the hydrophobic ring suggested an impact on channel gating. We investigated the effect of $\mathrm{N} 816 \mathrm{~K}$ mutation on biophysical properties of human Nav1.9 channels (hNav1.9 hereafter) when expressed in small DRG neurons from adult Nav1.9 $9^{-/-}$mice. Representative persistent TTX-R current traces for wild-type (WT) and N816K hNav1.9 channels are shown in Figures 2A,B, respectively. Figure 2C shows that N816K mutation lead to a significant increase in current density by 39\% (WT: $-129 \pm 12 \mathrm{pA} / \mathrm{pF}, n=18$; N816K: $-179 \pm 20 \mathrm{pA} / \mathrm{pF}, n=20$; $p=0.0467)$ (Table 1). The current-voltage (I-V) relationship of Nav1.9 channels is shown in Figure 2D. Normalized peak currents of WT and N816K channels were plotted against the voltage. Voltage-dependence of activation for Nav1.9 channels was shifted in a hyperpolarizing direction by the N816K mutation (Figure 2E). The activation midpoint of N816K mutant channel was significantly hyperpolarized by approximately $10 \mathrm{mV}$ (WT: $-44.7 \pm 2.2 \mathrm{mV}, n=13$; N816K: $-54.6 \pm 1.6 \mathrm{mV}, n=12$; $p=0.00164$ ), but the slope factor was unaffected (WT: $7.21 \pm 0.64 \mathrm{mV}, n=13$; N816K: $7.87 \pm 0.46 \mathrm{mV}, n=12$; $p=0.418)$ (Table 1). There was no statistical significance in midpoint voltage (WT: $-52.4 \pm 3.3 \mathrm{mV}, n=10 ; \mathrm{N} 816 \mathrm{~K}:-56.1 \pm 1.5 \mathrm{mV}$, $n=10 ; p=0.321$ ) or the slope factor (WT: $7.41 \pm 0.37 \mathrm{mV}$, $n=10$; N816K: $7.66 \pm 0.41 \mathrm{mV}, n=10 ; p=0.656$ ) for steadystate fast-inactivation between WT and N816K mutant channels (Table 1). The fraction of non-inactivating channel for N816K 
mutant channel was reduced but it did not reach statistical significance (WT: $15.2 \pm 3.0, n=10$; N816K: $8.56 \pm 2.1, n=10$; $p=0.0857)$ (Figure 2F).

\section{DRG Neuronal Excitability Is Increased by N816K Mutant Channels}

To assess the effects on the firing properties of DRG neurons resulting from the changes in biophysical properties of Nav1.9N816K channels, we studied excitability of small DRG neurons expressing either WT or N816K mutant hNav1.9 channel using current-clamp recordings. Figure 3A (left) shows a representative trace of spontaneous firing of action potentials, in the absence of external current stimulus, in a small DRG neuron expressing N816K mutant channel. Expression of N816K mutant channels did not change the percentage of spontaneously-firing neurons (WT: 10 out of 49 cells, 20\%; N816K, 11 out of 54 cells, $20 \%$, $p>0.999$ ) (Figure 3A, right). RMP was significantly depolarized by $7 \mathrm{mV}$ in small DRG neurons expressing N816K as compared

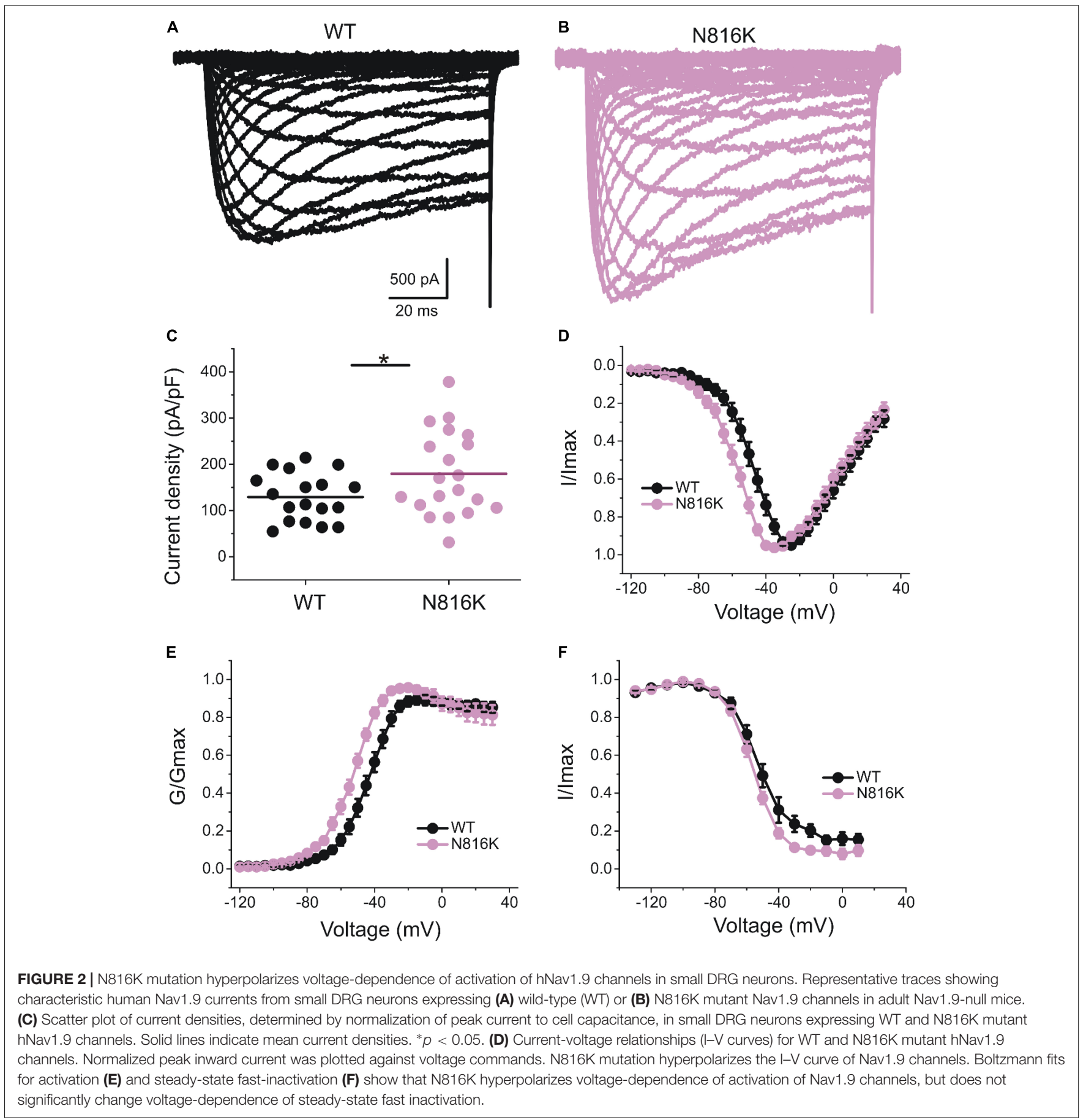


TABLE 1 | Biophysical properties of wild-type (WT) and mutant $\mathrm{Na}_{\mathrm{v}} 1.9$ channels in small DRG neurons.

\begin{tabular}{|c|c|c|c|c|c|c|c|c|c|}
\hline \multirow[t]{2}{*}{ Nav1.9 } & \multicolumn{2}{|c|}{ Current density } & \multicolumn{3}{|c|}{ Activation (mV) } & \multicolumn{4}{|c|}{ Steady-state fast inactivation (mV) } \\
\hline & $\mathrm{pA} / \mathrm{pF}$ & $\mathbf{n}$ & $\mathbf{V}_{1 / 2, \text { act }}$ & $\mathbf{k}$ & $\mathbf{n}$ & $V_{1 / 2, \text { fast }}$ & $\mathbf{k}$ & $A \%$ & $\mathbf{n}$ \\
\hline WT & $-129 \pm 12$ & 18 & $-44.7 \pm 2.2$ & $7.21 \pm 0.64$ & 13 & $-52.4 \pm 3.3$ & $7.41 \pm 0.37$ & $15.2 \pm 3.0$ & 10 \\
\hline N816K & $-179 \pm 20^{*}$ & 20 & $-54.6 \pm 1.6^{* *}$ & $7.87 \pm 0.46$ & 12 & $-56.1 \pm 1.5$ & $7.66 \pm 0.41$ & $8.56 \pm 2.1$ & 10 \\
\hline$p$-value & 0.0467 & & 0.00164 & 0.418 & & 0.321 & 0.656 & 0.0857 & \\
\hline
\end{tabular}

${ }^{*} p<0.05 ;{ }^{* *} p<0.01$ versus WT channels.

to WT channel (WT: $-52.2 \pm 1.1 \mathrm{mV}, n=39$; N816K: $45.1 \pm 1.2 \mathrm{mV}, n=43 ; p<0.001$ ) (Table 2 and Figure 3B). Expression of $\mathrm{N} 816 \mathrm{~K}$ channels also significantly reduced current threshold of action potential firing by 44\% (WT: $189 \pm 21 \mathrm{pA}$, $n=39$; N816K: $105 \pm 13 \mathrm{pA}, n=43$; $p<0.001$ ) (Table 2 and Figure $3 \mathrm{C}$ ). Figures $3 \mathrm{D}, \mathrm{E}$ show representative action potential traces in neurons expressing WT and N816K mutant channels, respectively. The DRG neuron expressing WT Nav1.9 channel in Figure 3D did not fire until the current stimulus reached 200 pA, which was defined as its current threshold, while expression of N816K channels lowered the current threshold to $55 \mathrm{pA}$ as shown in Figure 3E. In contrast to RMP depolarization and current threshold reduction by $\mathrm{N} 816 \mathrm{~K}$ mutant channel, there was no significant difference in input resistance (WT: $574 \pm 37 \mathrm{M} \Omega$, $n=39$; N816K: $571 \pm 34 \mathrm{M} \Omega, n=43 ; p=0.945)$ (Figure 3F), amplitude of action potential (WT: $117 \pm 2.3 \mathrm{mV}, n=39$; N816K: $111 \pm 2.0 \mathrm{mV}, n=43 ; p=0.0650$ ) (Figure 3G), halfwith of action potentials (WT: $6.84 \pm 0.41 \mathrm{~ms}, n=39$; N816K: $7.59 \pm 0.38 \mathrm{mV}, n=43 ; p=0.183$ ) (Figure $3 \mathrm{H}$ ), or afterhyperpolarization potential (AHP) (WT: $-62.6 \pm 0.77 \mathrm{mV}, n=39$; N816K: $-60.7 \pm 1.0 \mathrm{mV}, n=43 ; p=0.135$ ) (Figure $3 \mathrm{I}$ and Table 2). When a series of stimuli of $500 \mathrm{~ms}$ ranging from 25 to $500 \mathrm{pA}$ was applied, a significantly greater population of small DRG neurons expressing N816K mutant channels fired multiple action potentials compared to DRG neurons expressing WT channels (WT: 11 out of 39 cells, 28.2\%; N816K, 27 out of 43 cells, 62.8\%, $p=0.0017$ ) (Figure 4A). DRG neurons expressing $\mathrm{N} 816 \mathrm{~K}$ mutant channel are hyperexcitable as compared to those expressing WT Nav1.9 channels (Figure 4B). Representative traces in Figure 5 show that in response to $200 \mathrm{pA}$ current injection, a cell expressing WT Nav1.9 channel does not fire any all-or-none action potential within $500 \mathrm{~ms}$ (Figure 5A) while the other cell expressing N816K mutant channel does (Figure 5B). In response to greater stimuli at 350 and $500 \mathrm{pA}$, the cell expressing $\mathrm{N} 816 \mathrm{~K}$ is able to fire more action potentials (Figure 5B) than the one expressing WT Nav1.9 channel (Figure 5A).

\section{DISCUSSION}

We report here a novel mutation on SCN11A gene that encodes Nav1.9 channel, identified in a child with FEPS3. Our voltageclamp experiments demonstrated that the N816K mutation hyperpolarizes the voltage-dependence of activation of Nav1.9 channel by approximately $10 \mathrm{mV}$, a gain-of-function attribute underlying the proexcitatory effects of this mutation in small DRG neurons. To confirm this, we expressed N816K mutant channel in small DRG neurons and examined their excitability. We found that N816K mutant channels depolarized RMP by $7 \mathrm{mV}$, reduced current threshold for firing an all-or-none action potential by 44\%, and endowed DRG neurons with hyperexcitability in response to external stimuli as compared to the wild-type Nav1.9 channel. Thus, gain-of-function attributes at the channel and cellular levels could explain the pain phenotype in this patient.

Patients with Nav1.9-related pain syndromes or painless injuries have reported GI disturbances in addition to their pain syndrome (Bennett et al., 2019). Nav1.9 expression has also been shown in myenteric and submucosal plexuses in normal human colon, and reduced $\mathrm{Na}_{V} 1.9$ expression has been reported in ganglionic tissue from patients with Hirschsprung's disease (O'Donnell et al., 2016), supporting a contribution of $\mathrm{Na}_{\mathrm{V}} 1.9$ in GI function. This role of Nav1.9 is consistent with data from animal studies showing a role of this channel in regulating intestinal contraction (Hockley et al., 2014). Our patient reported chronic constipation from an early age, and abdominal pain, and thus conform to the FEPS3 phenotype.

It is remarkable that the proband's asymptomatic father is a carrier of the N816K mutation. An explanation based on sexual dimorphism is not supported by the reporting of pain in males with FEPS3 (Zhang et al., 2013; Okuda et al., 2016; Han et al., 2017). Variable penetrance is reported for several sodium channel mutations, especially for those with gain-of-function properties (Choi et al., 2010; Estacion et al., 2011). The reason for this high variability remains elusive, but may be explained by modifying genetic factors and/or exogenous triggers such as e.g., diabetes mellitus, infections, neurotoxic agents. However, we did not identify any potential triggers in the index patient nor additional rare variants in $\mathrm{Nav}_{v} 1.7, \mathrm{Nav} 1.8$, or $\mathrm{Na}_{v} 1.9$ which could have been considered as triggers. This clearly underlines the need for functional characterization of suspicious variants as done in this study to classify them as pathogenic (Waxman et al., 2014).

It is conceivable that the proband carries additional aggravating genetic variants in genes other than sodium channels, or, that the father is a carrier of a protective modifying variant(s) in other genes that mask the effect of the mutation. We have recently shown that a gain-of-function variant in Kv7.2 voltage-gated potassium channel contributes to amelioration of pain in a mother carrying the Nav1.7-S241T mutation which causes inherited erythromelalgia, compared to her son with the same Nav1.7 mutation but wild-type Kv7.2 (Mis et al., 2019). We also showed using dynamic clamp that substituting the M-current produced by the heterotetramer 


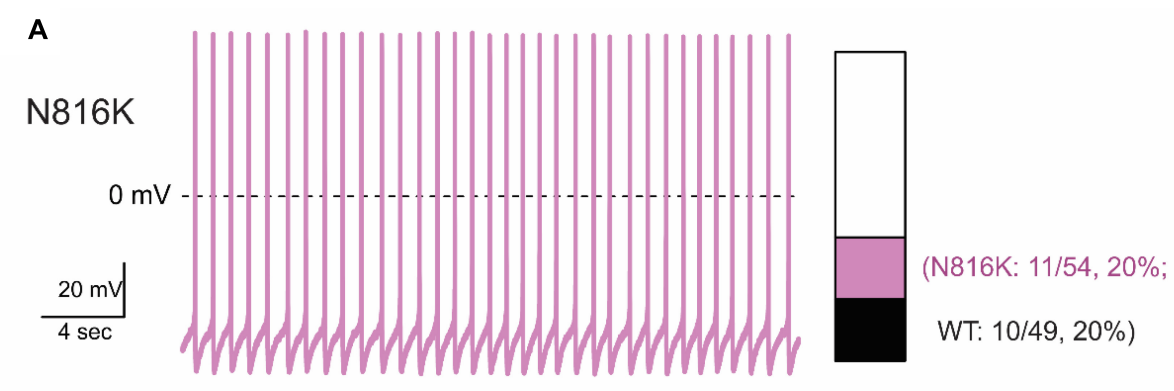

B

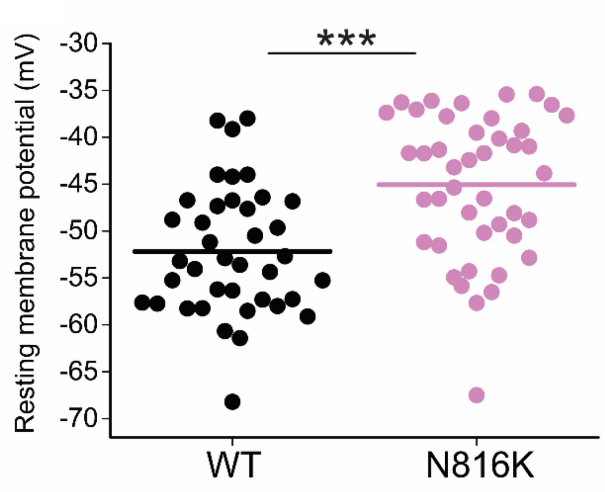

D
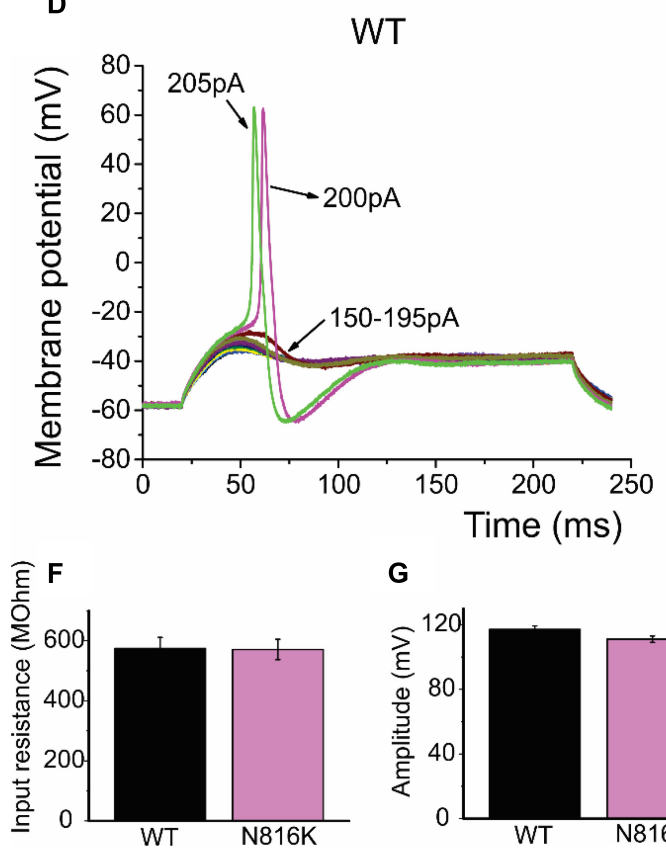

G

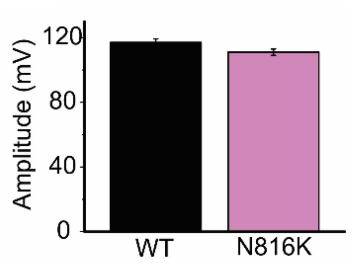

C

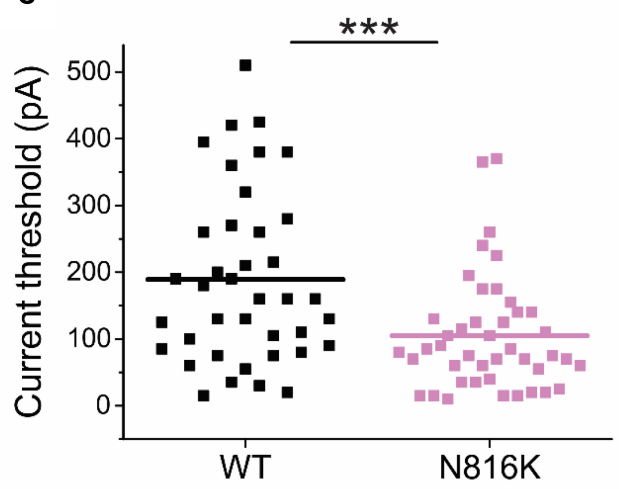

E

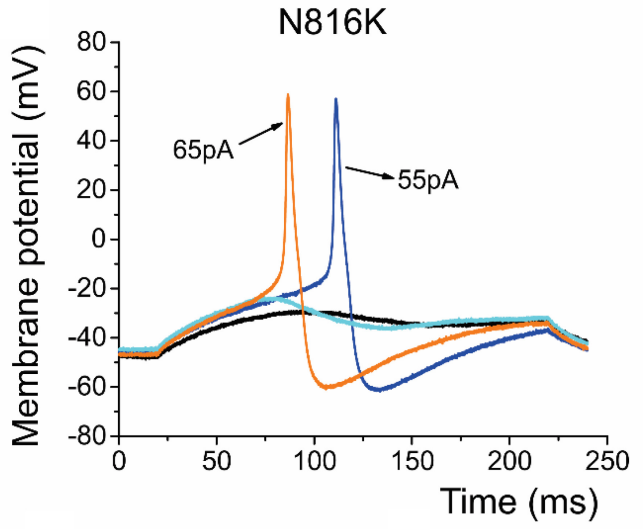

H

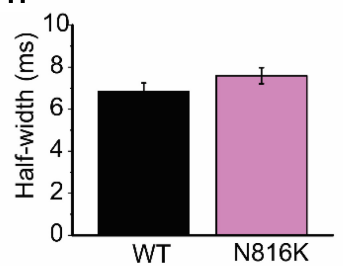

I

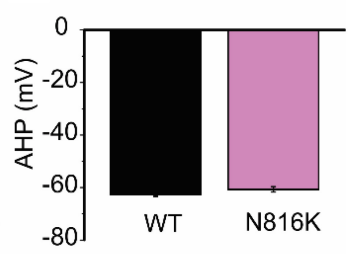

FIGURE 3 | N816K mutation depolarizes resting membrane and reduces threshold for action potentials in small DRG neurons. (A) A representative 30 s trace from a cell expressing N816K mutant channels demonstrates spontaneous firing of action potentials (left panel). However, N816K mutant channels do not change the proportion of spontaneously-firing cells, compared to WT hNav1.9 channels (right panel). (B) Scatter plot of resting membrane potential (RMP) in small DRG neurons expressing WT or N816K mutant hNav1.9 channels. Solid lines indicate mean RMP. ${ }^{* * *} p<0.001$. (C) Scatter plot of current threshold, the minimal current injection required to elicit an action potential in small DRG neurons expressing WT or N816K mutant hNav1.9 channels. Solid lines indicate mean RMP. *** $p<0.001$.

(D) Representative action potential traces recorded from a small DRG neuron expressing WT hNav1.9 channels show that the cell produces subthreshold depolarizations in response to current stimuli from 150 to $195 \mathrm{pA}$, and does not generate an all-or-none action potential until the injected current reaches 200 pA, which is defined as its current threshold. (E) Representative action potential traces recorded from a small DRG neuron expressing N816K mutant hNav1.9 channels show that the current threshold for this cell is 55 pA. (F) There is no significant difference in input resistance between WT and N816K mutant hNav1.9 channels. N816K mutation does not alter the waveforms of action potentials, indicated by (G) action potential amplitude, (H) after-hyperpolarization potential, or (I) half-width of action potentials. 
TABLE 2 | Action potential characterization for wild-type (WT) and mutant $\mathrm{Na}_{\mathrm{v}} 1.9$ channels in small DRG neurons.

\begin{tabular}{|c|c|c|c|c|c|c|c|}
\hline & Nav1.9 & RMP (mV) & $\begin{array}{c}\text { Input } \\
\text { resistance } \\
(\mathrm{M} \Omega)\end{array}$ & $\begin{array}{c}\text { Current } \\
\text { threshold } \\
\text { (pA) }\end{array}$ & $\begin{array}{c}\text { Amplitude } \\
\text { (mV) }\end{array}$ & $\begin{array}{c}\text { Half-width } \\
\text { (ms) }\end{array}$ & AHP (mV) \\
\hline WT & $n=39$ & $-52.2 \pm 1.1$ & $574 \pm 37$ & $189 \pm 21$ & $117 \pm 2.3$ & $6.84 \pm 0.41$ & $-62.6 \pm 0.77$ \\
\hline N816K & $n=43$ & $-45.1 \pm 1.2^{* * *}$ & $571 \pm 34$ & $105 \pm 13^{* * *}$ & $111 \pm 2.0$ & $7.59 \pm 0.38$ & $-60.7 \pm 1.0$ \\
\hline$p$-value & & $2.58 e-5$ & 0.945 & $7.70 e-4$ & 0.0650 & 0.183 & 0.135 \\
\hline
\end{tabular}

*** $p<0.001$ versus WT channels.

A

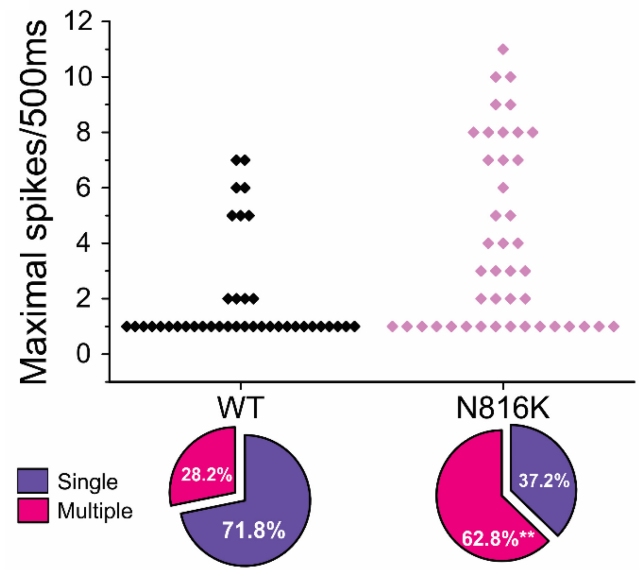

B

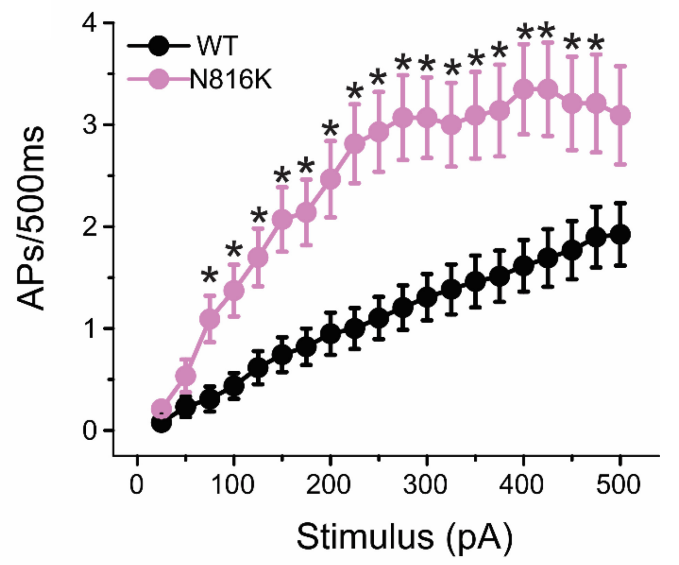

FIGURE 4 | N816K mutation enables hyperexcitability in small DRG neurons. (A) Scatter plot of maximal numbers of action potentials evoked by stimuli ranging from 25 to 500 pA in cells expressing WT and N816K mutant hNav1.9 channels. Cells are divided into two groups, those that only fire a single action potential during $500 \mathrm{~ms}$ course and those that fire multiple action potentials. N816K mutation increases the proportion of cells that fire multiple action potentials, compared to WT hNav1.9 channels. (B) Average action potential frequency during 500 ms current injections ranging from 25 to 500 pA in 25 pA increments. * $p<0.05$.

Kv7.2/Kv7.3 attenuates the excitability of sensory neurons that were differentiated from induced pluripotent stem cells (iPSC) of the son, further supporting the view that the gain-of-function mutation in Kv7.2 is protective against severe pain. Current iPSC differentiation strategies have not yielded detectable Nav1.9 currents (Eberhardt et al., 2015); thus studies of the impact of the mutation on the cellular behavior of sensory neurons that are differentiated from patient-specific iPSCs, and to possibly identify pain resilience genes in the father await improvements in differentiation protocols of sensory neurons that lead to the expression of a comparable set of ion channels as in mature sensory neurons.

Motor development in the proband was mildly slower than her older sister. Nav1.9 has been previously reported to be essential for activity-dependent axonal growth of mouse motoneurons in culture (Subramanian et al., 2012). Consistent with this finding, a motor deficit, muscular hypotonia, has been previously reported in patients carrying the L811P gain-of-function mutation in Nav1.9 which is associated with insensitivity to pain (Leipold et al., 2013; Woods et al., 2015; King et al., 2017). However, muscular hypotonia has not been reported in patients carrying gain-of-function mutation in Nav1.9 associated with increased pain (Okuda et al., 2016). Thus, whether the motor developmental delay in this patient with the Nav1.9-N816K gain-offunction mutation is coincidental or causative cannot be ascertained at this time.

Naproxen alleviated the pain for our patient carrying the N816K Nav1.9 mutation, similar to previously identified patients of FEPS3 who were also responsive to anti-inflammatory agents (Zhang et al., 2013; Leipold et al., 2015; Okuda et al., 2016). This suggests an inflammatory component of FEPS3, consistent with a role of Nav1.9 in inflammatory pain. Current density of Nav1.9 channels in DRG neurons was significantly increased upon exposure to PGE2 (Rush and Waxman, 2004), and underwent an approximately sixfold increase after exposure to an inflammatory cocktail that contains bradykinin, ATP, histamine, prostaglandin-E2, and norepinephrine (Maingret et al., 2008). Nav1.9 has been shown to potentiate the effects of oxidized phospholipids on excitability of nociceptors (Martin et al., 2018). Moreover, the engagement of Nav1.9 channel is required for developing inflammatory hypersensitivity. Thermal but not mechanical hypersensitivity was substantially diminished in Nav1.9 $9^{-/}$mice under peripheral inflammatory condition (Amaya et al., 2006). Heat and mechanical hypersensitivity were compromised in mice knocked down of Nav1.9 following subacute paw inflammation and chronic ankle inflammation (Lolignier et al., 2011). Excitatory responses to inflammatory 
mediators and subsequent mechanical hypersensitivity in colonic afferents have been reported to be attenuated in Nav1.9-/mice (Hockley et al., 2014), and the hypersensitivity of pelvic afferents in response to prostaglandin E2 was also diminished in Nav1.9 $9^{-/-}$mice (Ritter et al., 2009). These data from human and animal studies confirm a role for Nav1.9 in inflammatory pain, and suggest that data from preclinical animal studies might be translatable to humans.

Previous studies have characterized gain-of-function mutations A808G and L811P, which are located a few amino acid residues upstream of N816K. When expressed in ND7/23 cells, L811P shifted the voltage-dependence of activation by $-28 \mathrm{mV}$ and significantly increased the current density (Leipold et al., 2013). The A808G mutation increased current density of the channel without altering activation, however, voltagedependence of activation was assessed from -90 to $-50 \mathrm{mV}$ (Zhang et al., 2013); interpretation of the effect on voltage dependence is limited, however, because Nav1.9 activation does not peak at $-50 \mathrm{mV}$ as shown in our current study (Figure 2E). Nonetheless, N816K, along with A808G and L811P, within DII/S6 or near the juncture with L2, all demonstrate gain-offunction attributes in Nav1.9 channel, implicating structural significance of this region of interest in channel gating.

The mutation replaces an asparagine residue (N816) located in L2 proximal to the cytoplasmic terminus of DII S6 with a positively charged residue lysine (K816). The functional impact of this substitution cannot be simply inferred from sequence analysis because of the divergence of the corresponding residue among other human voltage-gated sodium channels (Ala or Ser residues, Figure 1). However, N816 is close to a highly conserved phenylalanine F814, which corresponds to F960 in hNav1.7, which participates in forming the hydrophobic ring lining the cytoplasmic aperture of Nav1.7, along with corresponding residues in the S6 segments of the other domains (Lampert et al., 2008), including the inherited erythromelalgia mutation DIV/F1449 (Dib-Hajj et al., 2005). Destabilization of the hydrophobic ring by the F1449V or F960V causes hyperpolarized activation of the mutant Nav1.7 channels, which we interpreted as a destabilization of the closed-state of the channel (Lampert et al., 2008). Nav1.9/F814 is only two amino acids away $(\sim 10 \AA)$ and the aromatic ring moiety will likely sense the nearby charge and form a dipole that would not occur with the normal N816 residue. This increased interaction induced by the N816K mutation could destabilize the closed state and contribute to the hyperpolarizing shift of activation voltage-dependence of the mutant channel, compared to wild-type Nav1.9. Alternatively, the interaction of the mutant channel with the membrane phospholipid bilayer could be altered by the introduction of the lysine residue at the cytoplasmic phase of the mutant channel pore. It has been previously shown that the interaction between membrane phospholipids with ion channels provide energetic stability and proper functioning of these channels (Schmidt et al., 2006; Xu et al., 2008; Hite et al., 2014; Ahuja et al., 2015). Further work is needed to distinguish between these two models.

This study expands the spectrum of Nav1.9-linked abnormality in nociception and confirms the significant role of the Nav1.9 channel in pain signaling. We show that the N816K mutation is likely to alter the local structure of the
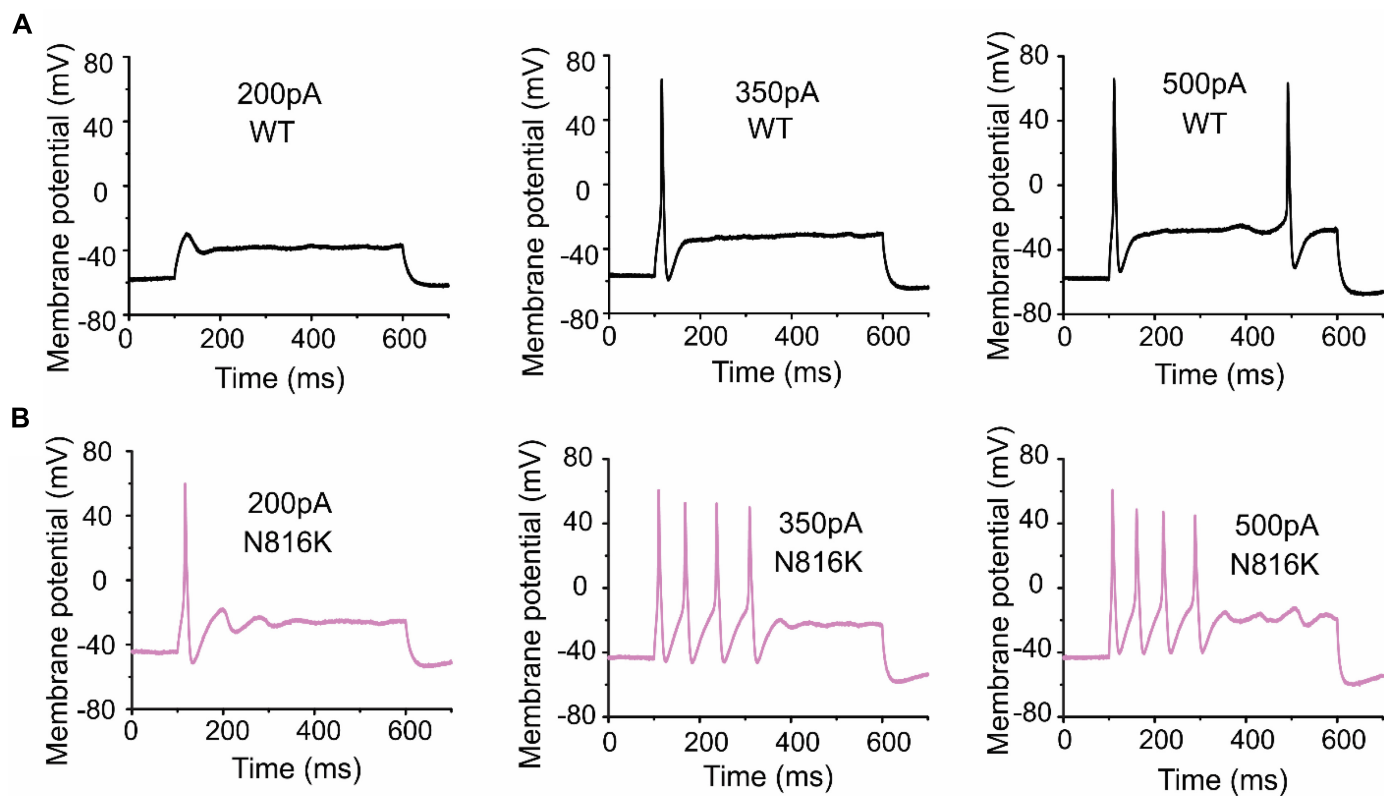

FIGURE 5 | A small DRG neuron expressing N816K mutant hNav1.9 channels produces more action potentials than WT in response to the same stimuli. Representative action potential traces from a small DRG neuron expressing (A) WT or (B) N816K mutant hNav1.9 channels in response to 200 , 350 , and 500 pA current stimuli, respectively. 
activation gate, confers gain-of-function attributes on Nav1.9 channels, which lead to hyperexcitability in small DRG neurons, is consistent with the pain experience by our patient. Thus, development of Nav1.9 specific inhibitors holds promise for effective pain management in the future. Moreover, side-effects could be minimal due to the low homology in sequence between Nav1.9 and other voltage-gated sodium channel isoforms, as well as the preferential expression of Nav1.9 in nociceptors in peripheral nervous system.

\section{DATA AVAILABILITY}

The datasets generated for this study are available on request to the corresponding author.

\section{ETHICS STATEMENT}

Human Subject Research: The studies involving human participants were reviewed and approved by the Yale Human Research Protection Program Institutional Review Boards and by the local ethics committee at the Uniklinik under an approved institutional review board. Written informed consent to participate in this study was provided by the participants' legal guardian/next of kin. Animal Subjects: The animal study was reviewed and approved by the VA-CT Institutional Animal Care Use Committee.

\section{REFERENCES}

Ahuja, S., Mukund, S., Deng, L., Khakh, K., Chang, E., Ho, H., et al. (2015). Structural basis of Nav1.7 inhibition by an isoform-selective small-molecule antagonist. Science 350:aac5464. doi: 10.1126/science.aac5464

Amaya, F., Wang, H., Costigan, M., Allchorne, A. J., Hatcher, J. P., Egerton, J., et al. (2006). The voltage-gated sodium channel Nav1.9 is an effector of peripheral inflammatory pain hypersensitivity. J. Neurosci. 26, 12852-12860. doi: 10.1523/jneurosci.4015-06.2006

Atkins, J. F., Wills, N. M., Loughran, G., Wu, C. Y., Parsawar, K., Ryan, M. D. et al. (2007). A case for "StopGo": reprogramming translation to augment codon meaning of GGN by promoting unconventional termination (Stop) after addition of glycine and then allowing continued translation (Go). RNA 13, 803-810. doi: 10.1261/rna.487907

Bennett, D. L., Clark, A. J., Huang, J., Waxman, S. G., and Dib-Hajj, S. D. (2019). The role of voltage-gated sodium channels in pain signaling. Physiol. Rev. 99, 1079-1151. doi: 10.1152/physrev.00052.2017

Black, J. A., and Waxman, S. G. (2002). Molecular identities of two tetrodotoxinresistant sodium channels in corneal axons. Exp. Eye Res. 75, 193-199. doi: 10.1006/exer.2002.2014

Choi, J. S., Cheng, X., Foster, E., Leffler, A., Tyrrell, L., Te Morsche, R. H., et al. (2010). Alternative splicing may contribute to time-dependent manifestation of inherited erythromelalgia. Brain 133, 1823-1835. doi: 10.1093/brain/ awq114

Coste, B., Osorio, N., Padilla, F., Crest, M., and Delmas, P. (2004). Gating and modulation of presumptive NaV1.9 channels in enteric and spinal sensory neurons. Mol. Cell Neurosci. 26, 123-134. doi: 10.1016/j.mcn.2004.01.015

Cummins, T. R., Dib-Hajj, S. D., Black, J. A., Akopian, A. N., Wood, J. N., and Waxman, S. G. (1999). A novel persistent tetrodotoxin-resistant sodium current In SNS-null and wild-type small primary sensory neurons. J. Neurosci. 19:RC43.

Dib-Hajj, S. D., Choi, J. S., Macala, L. J., Tyrrell, L., Black, J. A., Cummins, T. R., et al. (2009). Transfection of rat or mouse neurons by biolistics or electroporation. Nat. Protoc. 4, 1118-1126. doi: 10.1038/nprot.2009.90

\section{AUTHOR CONTRIBUTIONS}

JH performed the electrophysiological recordings, analyzed the data, and prepared the graphs. ME performed the in silico modeling of Nav1.9 channel. PZ isolated and transfected the primary neurons. FD-H provided the critical reagents. BS consented and enrolled the family in this study. KB provided the clinical data. AA and IK identified the N816K mutation of hNav1.9 channel in this family. SD-H and SW designed and supervised the project. All authors contributed to the writing of the manuscript.

\section{FUNDING}

This work was supported by the Medical Research Service and Rehabilitation Research Service, Department of Veterans Affairs (SW and SD-H). The Center for Neuroscience and Regeneration/Rehabilitation Research is a collaboration of the Paralyzed Veterans of America with Yale University.

\section{ACKNOWLEDGMENTS}

We thank the family for participating in this study. We also thank Dr. Jun-hui Yuan for the helpful discussions and Palak Shah for the technical support.

Dib-Hajj, S. D., Rush, A. M., Cummins, T. R., Hisama, F. M., Novella, S., Tyrrell, L., et al. (2005). Gain-of-function mutation in Nav1.7 in familial erythromelalgia induces bursting of sensory neurons. Brain 128, 1847-1854. doi: 10.1093/brain/ awh514

Dib-Hajj, S. D., Tyrrell, L., Black, J. A., and Waxman, S. G. (1998). NaN, a novel voltage-gated $\mathrm{Na}$ channel, is expressed preferentially in peripheral sensory neurons and down-regulated after axotomy. Proc. Natl. Acad. Sci. U.S.A. 95, 8963-8968. doi: 10.1073/pnas.95.15.8963

Dib-Hajj, S. D., Tyrrell, L., Cummins, T. R., Black, J. A., Wood, P. M., and Waxman, S. G. (1999). Two tetrodotoxin-resistant sodium channels in human dorsal root ganglion neurons. FEBS Lett. 462, 117-120. doi: 10.1016/s0014-5793(99) 01519-7

Eberhardt, E., Havlicek, S., Schmidt, D., Link, A. S., Neacsu, C., Kohl, Z., et al. (2015). Pattern of functional TTX-Resistant sodium channels reveals a developmental stage of human iPSC- and ESC-Derived nociceptors. Stem Cell Rep. 5, 305-313. doi: 10.1016/j.stemcr.2015.07.010

Estacion, M., Han, C., Choi, J. S., Hoeijmakers, J. G., Lauria, G., Drenth, J. P., et al. (2011). Intra- and interfamily phenotypic diversity in pain syndromes associated with a gain-of-function variant of NaV1.7. Mol. Pain 7:92. doi: 10. 1186/1744-8069-7-92

Fjell, J., Hjelmstrom, P., Hormuzdiar, W., Milenkovic, M., Aglieco, F., Tyrrell, L., et al. (2000). Localization of the tetrodotoxin-resistant sodium channel NaN in nociceptors. Neuroreport 11, 199-202. doi: 10.1097/00001756-20000117000039

Han, C., Yang, Y., De Greef, B. T., Hoeijmakers, J. G., Gerrits, M. M., Verhamme, C., et al. (2015). The Domain II S4-S5 Linker in Nav1.9: a missense mutation enhances activation, impairs fast inactivation, and produces human painful neuropathy. Neuromolecular Med. 17, 158-169. doi: 10.1007/s12017-0158347-9

Han, C., Yang, Y., Te Morsche, R. H., Drenth, J. P., Politei, J. M., Waxman, S. G., et al. (2017). Familial gain-of-function Nav1.9 mutation in a painful channelopathy. J. Neurol. Neurosurg. Psychiatry 88, 233-240. doi: 10.1136/jnnp2016-313804 
Hite, R. K., Butterwick, J. A., and Mackinnon, R. (2014). Phosphatidic acid modulation of Kv channel voltage sensor function. eLife 3:e04366. doi: 10.7554/ eLife.04366

Hockley, J. R., Boundouki, G., Cibert-Goton, V., Mcguire, C., Yip, P. K., Chan, C., et al. (2014). Multiple roles for Na1.9 in the activation of visceral afferents by noxious inflammatory, mechanical, and human disease-derived stimuli. Pain 155, 1962-1975. doi: 10.1016/j.pain.2014.06.015

Huang, J., Han, C., Estacion, M., Vasylyev, D., Hoeijmakers, J. G., Gerrits, M. M., et al. (2014). Gain-of-function mutations in sodium channel Nav1.9 in painful neuropathy. Brain 137, 1627-1642. doi: 10.1093/brain/awu079

Huang, J., Vanoye, C. G., Cutts, A., Goldberg, Y. P., Dib-Hajj, S. D., Cohen, C. J., et al. (2017). Sodium channel NaV1.9 mutations associated with insensitivity to pain dampen neuronal excitability. J. Clin. Invest. 127, 2805-2814. doi: 10.1172/ JCI92373

King, M. K., Leipold, E., Goehringer, J. M., Kurth, I., and Challman, T. D. (2017). Pain insensitivity: distal S6-segment mutations in NaV1.9 emerge as critical hotspot. Neurogenetics 18, 179-181. doi: 10.1007/s10048-017-0513-9

Lampert, A., O'reilly, A. O., Dib-Hajj, S. D., Tyrrell, L., Wallace, B. A., and Waxman, S. G. (2008). A pore-blocking hydrophobic motif at the cytoplasmic aperture of the closed-state Nav1.7 channel is disrupted by the erythromelalgiaassociated F1449V mutation. J. Biol. Chem. 283, 24118-24127. doi: 10.1074/jbc. M802900200

Leipold, E., Hanson-Kahn, A., Frick, M., Gong, P., Bernstein, J. A., Voigt, M., et al. (2015). Cold-aggravated pain in humans caused by a hyperactive NaV1.9 channel mutant. Nat. Commun. 6:10049. doi: 10.1038/ncomms10049

Leipold, E., Liebmann, L., Korenke, G. C., Heinrich, T., Giesselmann, S., Baets, J., et al. (2013). A de novo gain-of-function mutation in SCN11A causes loss of pain perception. Nat. Genet. 45, 1399-1404. doi: 10.1038/ng.2767

Lolignier, S., Amsalem, M., Maingret, F., Padilla, F., Gabriac, M., Chapuy, E., et al. (2011). Nav1.9 channel contributes to mechanical and heat pain hypersensitivity induced by subacute and chronic inflammation. PLoS One 6:e23083. doi: 10.1371/journal.pone.0023083

Luke, G. A., De Felipe, P., Lukashev, A., Kallioinen, S. E., Bruno, E. A., and Ryan, M. D. (2008). Occurrence, function and evolutionary origins of '2A-like' sequences in virus genomes. J. Gen. Virol. 89, 1036-1042. doi: 10.1099/vir.0. 83428-0

Maingret, F., Coste, B., Padilla, F., Clerc, N., Crest, M., Korogod, S. M., et al. (2008). Inflammatory mediators increase Nav1.9 current and excitability in nociceptors through a coincident detection mechanism. J. Gen. Physiol. 131, 211-225. doi: 10.1085/jgp.200709935

Martin, C., Stoffer, C., Mohammadi, M., Hugo, J., Leipold, E., Oehler, B., et al. (2018). NaV1.9 Potentiates Oxidized Phospholipid-Induced TRP responses only under inflammatory conditions. Front. Mol. Neurosci. 11:7. doi: 10.3389/ fnmol.2018.00007

Mis, M. A., Yang, Y., Tanaka, B. S., Gomis-Perez, C., Liu, S., Dib-Hajj, F., et al. (2019). Resilience to pain: a peripheral component identified using induced pluripotent stem cells and dynamic clamp. J. Neurosci. 39, 382-392. doi: 10. 1523/JNEUROSCI.2433-18.2018

O’Brien, B. J., Caldwell, J. H., Ehring, G. R., Bumsted O’brien, K. M., Luo, S., and Levinson, S. R. (2008). Tetrodotoxin-resistant voltage-gated sodium channels $\mathrm{Na}(\mathrm{v}) 1.8$ and $\mathrm{Na}(\mathrm{v}) 1.9$ are expressed in the retina. J. Comp. Neurol. 508, 940-951. doi: 10.1002/cne.21701

O’Donnell, A. M., Coyle, D., and Puri, P. (2016). Decreased Nav1.9 channel expression in Hirschsprung's disease. J. Pediatr. Surg. 51, 1458-1461. doi: 10. 1016/j.jpedsurg.2016.05.007

Okuda, H., Noguchi, A., Kobayashi, H., Kondo, D., Harada, K. H., Youssefian, S., et al. (2016). Infantile pain episodes associated with novel Nav1.9 mutations in familial episodic pain syndrome in japanese families. PLoS One 11:e0154827. doi: 10.1371/journal.pone.0154827

Osorio, N., Korogod, S., and Delmas, P. (2014). Specialized functions of nav1.5 and nav1.9 channels in electrogenesis of myenteric neurons in intact mouse Ganglia. J. Neurosci. 34, 5233-5244. doi: 10.1523/JNEUROSCI.0057-14. 2014

Padilla, F., Couble, M. L., Coste, B., Maingret, F., Clerc, N., Crest, M., et al. (2007). Expression and localization of the Nav1.9 sodium channel in enteric neurons and in trigeminal sensory endings: implication for intestinal reflex function and orofacial pain. Mol. Cell Neurosci. 35, 138-152. doi: 10.1016/j.mcn.2007. 02.008

Ritter, A. M., Martin, W. J., and Thorneloe, K. S. (2009). The voltagegated sodium channel Nav1.9 is required for inflammation-based urinary bladder dysfunction. Neurosci. Lett. 452, 28-32. doi: 10.1016/j.neulet.2008. 12.051

Rugiero, F., Mistry, M., Sage, D., Black, J. A., Waxman, S. G., Crest, M., et al. (2003). Selective expression of a persistent tetrodotoxin-resistant $\mathrm{Na}+$ current and NaV1.9 subunit in myenteric sensory neurons. J. Neurosci. 23, 2715-2725. doi: 10.1523/jneurosci.23-07-02715.2003

Rush, A. M., and Waxman, S. G. (2004). PGE2 increases the tetrodotoxin-resistant Nav1.9 sodium current in mouse DRG neurons via G-proteins. Brain Res. 1023, 264-271. doi: 10.1016/j.brainres.2004.07.042

Ryan, M. D., and Drew, J. (1994). Foot-and-mouth disease virus 2A oligopeptide mediated cleavage of an artificial polyprotein. EMBO J. 13, 928-933. doi: 10. 1002/j.1460-2075.1994.tb06337.x

Schmidt, D., Jiang, Q. X., and Mackinnon, R. (2006). Phospholipids and the origin of cationic gating charges in voltage sensors. Nature 444, 775-779. doi: 10.1038 /nature05416

Subramanian, N., Wetzel, A., Dombert, B., Yadav, P., Havlicek, S., Jablonka, S., et al. (2012). Role of $\mathrm{Na}(\mathrm{v}) 1.9$ in activity-dependent axon growth in motoneurons. Hum. Mol. Genet. 21, 3655-3667. doi: 10.1093/hmg/ dds 195

Waxman, S. G., Merkies, I. S., Gerrits, M. M., Dib-Hajj, S. D., Lauria, G., Cox, J. J., et al. (2014). Sodium channel genes in pain-related disorders: phenotypegenotype associations and recommendations for clinical use. Lancet Neurol. 13, 1152-1160. doi: 10.1016/S1474-4422(14)70150-4

Woods, C. G., Babiker, M. O., Horrocks, I., Tolmie, J., and Kurth, I. (2015). The phenotype of congenital insensitivity to pain due to the NaV1.9 variant p.L811P. Eur. J. Hum. Genet. 23, 561-563. doi: 10.1038/ejhg.2014.166

Xu, Y., Ramu, Y., and Lu, Z. (2008). Removal of phospho-head groups of membrane lipids immobilizes voltage sensors of K+ channels. Nature 451, 826-829. doi: 10.1038/nature06618

Zhang, X. Y., Wen, J., Yang, W., Wang, C., Gao, L., Zheng, L. H., et al. (2013). Gainof-Function mutations in SCN11A cause familial episodic pain. Am. J. Hum. Genet. 93, 957-966. doi: 10.1016/j.ajhg.2013.09.016

Conflict of Interest Statement: The authors declare that the research was conducted in the absence of any commercial or financial relationships that could be construed as a potential conflict of interest.

Copyright (c) 2019 Huang, Estacion, Zhao, Dib-Hajj, Schulman, Abicht, Kurth, Brockmann, Waxman and Dib-Hajj. This is an open-access article distributed under the terms of the Creative Commons Attribution License (CC BY). The use, distribution or reproduction in other forums is permitted, provided the original author(s) and the copyright owner(s) are credited and that the original publication in this journal is cited, in accordance with accepted academic practice. No use, distribution or reproduction is permitted which does not comply with these terms. 